\title{
Cell Therapy in Chagas Cardiomyopathy (Chagas Arm of the Multicenter Randomized Trial of Cell Therapy in Cardiopathies Study)
}

\section{A Multicenter Randomized Trial}

Ricardo Ribeiro dos Santos, MD, PhD; Salvador Rassi, MD; Gilson Feitosa, MD;

Oswaldo T. Grecco, MD; Anis Rassi, Jr, MD; Ademir B. da Cunha, MD; Valéria B. de Carvalho, MD;

Luiz César Guarita-Souza, MD; Wilson de Oliveira, Jr, MD; Bernardo R. Tura, MD, PhD;

Milena B.P. Soares, PhD; Antonio C. Campos de Carvalho, MD, PhD;

for the Chagas Arm of the MiHeart Study Investigators

Background-Previous studies suggested that transplantation of autologous bone marrow-derived mononuclear cells (BMNCs) improves heart function in chronic chagasic cardiomyopathy. We report the results of the first randomized trial of BMNC therapy in chronic chagasic cardiomyopathy.

Methods and Results-Patients 18 to 75 years of age with chronic chagasic cardiomyopathy, New York Heart Association class II to IV heart failure, left ventricular ejection fraction (LVEF) $<35 \%$, and optimized therapy were randomized to intracoronary injection of autologous BMNCs or placebo. The primary end point was the difference in LVEF from baseline to 6 and 12 months after treatment between groups. Analysis was by intention to treat and powered to detect an absolute between-group difference of 5\%. Between July 2005 and October 2009, 234 patients were enrolled. Two patients abandoned the study and 49 were excluded because of protocol violation. The remaining 183 patients, 93 in the placebo group and 90 in the BMNC group, had a trimmed mean age of 52.4 years (range, 50.8-54.0 years) and LVEF of 26.1\% (range, 25.1\%-27.1\%) at baseline. Median number of injected BMNCs was $2.20 \times 10^{8}$ (range, $1.40-3.50 \times 10^{8}$ ). Change in LVEF did not differ significantly between treatment groups: trimmed mean change in LVEF at 6 months, $3.0(1.3-4.8)$ for BMNCs and $2.5(0.6-4.5)$ for placebo $(P=0.519)$; change in LVEF at 12 months, $3.5(1.5-5.5)$ for BMNCs and $3.7(1.5-6.0)$ for placebo $(P=0.850)$. Left ventricular systolic and diastolic volumes, New York Heart Association functional class, Minnesota quality-of-life questionnaire, brain natriuretic peptide concentrations, and 6-minute walking test did also not differ between groups.

Conclusion-Intracoronary injection of autologous BMNCs does not improve left ventricular function or quality of life in patients with chronic chagasic cardiomyopathy.

Clinical Trial Registration-URL: http://www.clinicaltrials.gov. Unique identifier: NCT00349271.

(Circulation. 2012;125:2454-2461.)

Key Words: cardiomyopathies @ Chagas cardiomyopathy @ stem cells @ tissue therapy

$\mathrm{C}$ hagasic cardiomyopathy, which affects $\approx 1.6$ to 2.4 million people and results in an estimated 12500 deaths every year, is a leading cause of heart failure in Latin America. ${ }^{1}$ The disease is caused by infection with the parasite Trypanosoma cruzi, which is transmitted to humans mainly by triatominae insects or occasionally by nonvectorial mechanisms such as blood transfusion and vertically from mother to infant. ${ }^{2}$ Cardiac manifestations, which appear 10 to 30 years after primary infection during the chronic phase of the disease, are attributed to multifactorial causes, including parasite persistence, vascular impairment, destruction of ganglia of the autonomic nervous system, and autoimmunity. ${ }^{3}$ Cardiomyopathy is characterized by focal or disseminated inflammatory infiltrates, myocytolysis, myo-

Received September 27, 2011; accepted April 5, 2012.

From the Hospital San Rafael, Salvador (R.R.d.S., M.B.P.S.); Hospital das Clínicas de Goiania, Gioania (S.R.); Hospital Santa Izabel, Salvador (G.F.); Instituto de Moléstias Cardiovasculares, São José do Rio Preto (O.T.G.); Hospital do Coração Anis Rassi, Goiania (A.R.); Instituto Nacional de Cardiologia, Rio de Janeiro (A.B.d.C., B.R.T., A.C.C.d.C.); Hospital Sírio-Libanes, São Paulo (V.B.d.C.); Pontifícia Universidade Católica do Paraná, Curitiba (L.C.G.-S.); and Pronto Socorro Cardiológico de Pernambuco, Recife (W.d.O.), Brazil.

The online-only Data Supplement is available with this article at http://circ.ahajournals.org/lookup/suppl/doi:10.1161/CIRCULATIONAHA. 111.067785/-/DC1.

Correspondence to Antonio C. Campos de Carvalho, PhD, Instituto Nacional de Cardiologia, Rua das Laranjeiras, 374, CEP 22240 006, Rio de Janeiro, RJ Brasil. E-mail acarlos@biof.ufrj.br

(C) 2012 American Heart Association, Inc. 


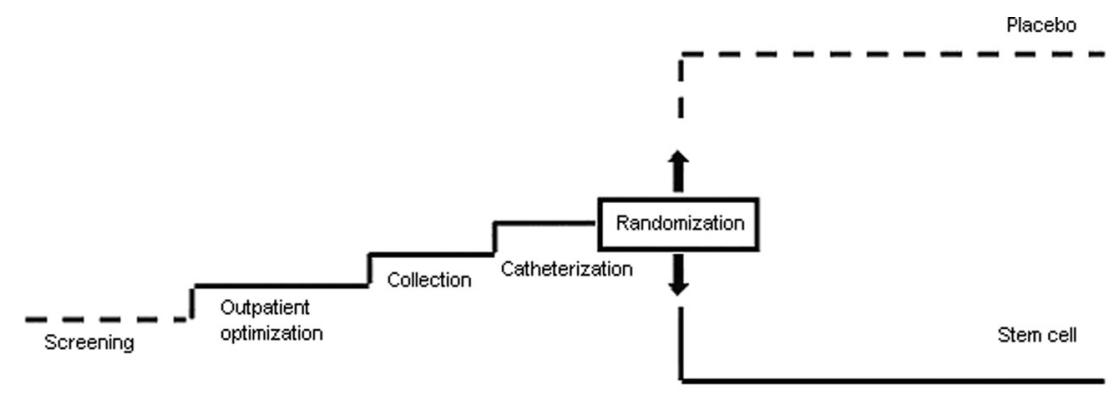

Figure 1. Time chart of the study. Patients were screened for eligibility before optimization of pharmacological therapy for at least 6 weeks. Assessment of patients at baseline was followed by bone marrow aspiration and then catheterization. Catheterization was the last step for inclusion of patients because coronary artery disease was an exclusion criterion. Patients included in the study were randomized to receive bone mar-

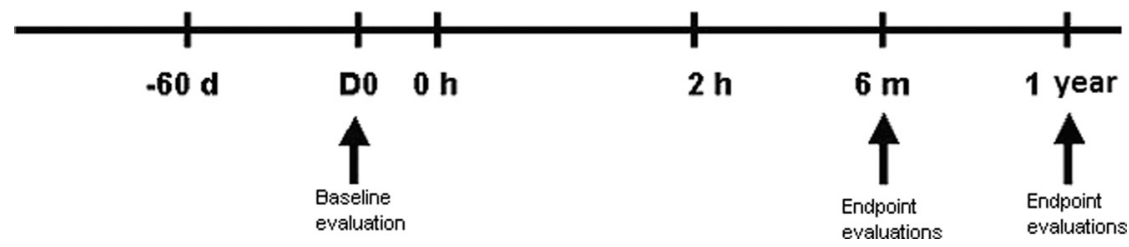
row-derived mononuclear cells (BMNCs) or placebo and were followed up for 12 months.

necrosis, and progressive fibrosis, resulting in damage to the extracellular matrix and replacement of cardiac myocytes and vascular cells by fibrous tissue, with remodeling of the myocardium and vasculature. ${ }^{4,5}$

\section{Clinical Perspective on p 2461}

Chronic chagasic cardiomyopathy (CCC) is treated like all other heart failure syndromes; therapy usually includes $\beta$-blockers, diuretics, angiotensin-converting enzyme inhibitors (or angiotensin receptor blockers), and spironolactone. $\mathrm{CCC}$ has also been reported to be the main prognostic factor of mortality in patients with heart failure of different causes. ${ }^{6}$ When disease progresses, heart transplantation remains one of the few valuable therapeutic options. However, this option is limited by the small number of donors and the complications of immunosuppressive therapy, including parasite reactivation. New therapeutic interventions are clearly needed, and cell transplantation has emerged as an adjunct to standard therapy. Pioneering studies by Soares and colleagues ${ }^{7}$ in a mouse model of CCC and by Vilas-Boas et al ${ }^{8,9}$ to assess safety in patients with CCC proved intracoronary injection of autologous bone marrow-derived mononuclear cells (BMNCs) to be safe and feasible.

We performed a multicenter, double-blind, placebocontrolled randomized trial to assess the efficacy of BMNC therapy for improvement of left ventricular ejection fraction (LVEF) in patients with CCC and severe heart failure. We targeted this population because it was the focus of the safety study and because LVEF has been shown to be an independent predictor of mortality in patients with chronic heart failure secondary to chagasic cardiomyopathy. ${ }^{10}$

\section{Methods}

\section{Patients}

The study sample was selected consecutively from CCC patients who attended outpatient clinics in 11 specialized centers in Brazil. Patients meeting all of the following criteria were eligible for the study: previous diagnosis of heart failure according to the Framingham criteria receiving active and regular follow-up at a cardiac center with an etiologic diagnosis of Chagas disease confirmed by 2 serological tests using distinct methods, age of 18 to 75 years, New York Heart Association (NYHA) functional class II to IV heart failure, and echocardiogram showing LVEF of $<35 \%$ by the Simpson rule. Women also had to have a negative serum pregnancy test during the screening phase, had to have been postmenopausal for at least 1 year, or had to be surgically sterile (bilateral tubal ligation, bilateral oophorectomy, or hysterectomy).

Patients meeting any of the following criteria were ineligible for the study: valvular heart disease except for functional mitral or tricuspid regurgitation; coronary angiography showing a clinically significant lesion ( $\geq 50 \%$ lumen obstruction in 1 or more coronary arteries); sustained ventricular tachycardia episodes diagnosed previously; alcohol or drug abuse; serum creatinine of $>221 \mu \mathrm{mol} / \mathrm{L}$ or previous dialysis therapy; evidence of acute systemic infection; valvular heart disease (severe aortic stenosis, gradient of left ventricle to aorta $>50 \mathrm{~mm} \mathrm{Hg}$, mean stenosis $<1.5 \mathrm{~cm}^{2}$, or aortic or mitral regurgitation); chronic obstructive pulmonary disease with continuous use of steroids or bronchodilators; liver, blood, and neoplastic diseases or hemostasis disorders; chronic inflammatory or infectious diseases; other diseases that could affect life expectancy; or any other comorbidity affecting 2-year survival.

All patients enrolled in the study provided signed informed consent. The study was approved by the national and local ethics committees.

\section{Procedures}

Figure 1 shows the progression of patients through the study. For at least 6 weeks before the eligibility assessment, pharmacological therapy was optimized for all patients by identification of maximum tolerated doses of each drug. Unless required, optimal doses were not altered during the study. Appropriate drug treatment for heart failure in CCC was defined as the use, whenever possible, of the following drugs: digoxin $(0 \cdot 125-0 \cdot 25 \mathrm{mg} / \mathrm{d})$; spironolactone $(25 \mathrm{mg} / \mathrm{d})$; hydrochlorothiazide $(12.5-50 \mathrm{mg} / \mathrm{d})$ and/or furosemide (minimum of 40 $\mathrm{mg} / \mathrm{d})$; enalapril (5-40 mg/d) or captopril (37.5-150 mg/d); losartan $(50-150 \mathrm{mg} / \mathrm{d})$; hydralazine $(75 \mathrm{mg} / \mathrm{d})$ with isosorbide mononitrate $(20 \mathrm{mg} / \mathrm{d})$ for patients intolerant of angiotensin-converting enzyme inhibitors or angiotensin receptor blockers; carvedilol (6.25-50 $\mathrm{mg} / \mathrm{d})$; and amiodarone (200-400 mg/d). All drugs were dispensed free of charge to enrolled patients.

After the eligibility assessment but before randomization, all patients had bone marrow aspiration and catheterization to allow exclusion of patients with coronary artery disease and to ensure that masking was maintained once treatments were assigned. Bone marrow content $(100 \mathrm{~mL})$ was aspirated under sedation and local anesthesia by iliac crest puncture. An enriched BMNC fraction was obtained by Ficoll Hystopaque gradient centrifugation (GE Healthcare, Uppsala, Sweden) and resuspended in sterile 5\% glucose saline solution. This procedure was repeated twice, after which the BMNCs were resuspended in saline solution containing 5\% autologous serum. BMNC populations were characterized by flow cytometry by 
use of a FACSCanto cytometer (BD Biosciences, San Diego, CA). After BMNC preparation, each participating center sent a sample to the flow cytometry core laboratory at the National Cardiology Institute (Rio de Janeiro, Brazil). Cells were counted in a hemocytometer (Coulter, Miami, FL) and then labeled with a panel of 23 antibodies (Table I in the online-only Data Supplement) to characterize cell populations present in the BMNC fraction.

Within 2.5 to 3 hours of bone marrow aspiration, a syringe containing the randomly assigned treatment was sent to the catheter laboratory for intracoronary injection, thereby avoiding the need for a second catheterization. Saline with 5\% autologous serum was used as the placebo treatment. In the BMNC group, a minimum target of $10^{8}$ BMNCs diluted in $20 \mathrm{~mL}$ saline solution was slowly injected into all coronary arteries with an angioplasty catheter without balloon inflation over a period of 10 minutes: $10 \mathrm{~mL}$ in the anterior descending artery, $5 \mathrm{~mL}$ in right coronary artery, and $5 \mathrm{~mL}$ in the circumflex artery in case of right dominance; and $10 \mathrm{~mL}$ in the anterior descending artery, $8 \mathrm{~mL}$ in the circumflex artery, and $2 \mathrm{~mL}$ in the right coronary artery in case of left dominance. Twenty-five days after BMNC infusion, $5 \mu \mathrm{g} / \mathrm{kg}$ per day filgrastim (granulocyte colony-stimulating factor) or its placebo was administered for 5 days. After catheterization, all patients stayed for 24 hours in the intensive care unit and then for 72 hours in the hospital ward. If no complications ensued, patients were discharged from hospital. During their stay in the intensive care unit, concentrations of creatinine kinase-MB and troponin I were measured at 6 and 12 hours after catheterization.

\section{Outcomes}

Assessments done at baseline and at 6 and 12 months of follow-up consisted of clinical examination, chest radiography, ECG, biochemistry and hematology, brain natriuretic peptide (BNP) concentration, echocardiography, 6-minute walk test, and 24-hour Holter monitoring. Clinical assessments included physical examination, blood pressure, Minnesota quality-of-life questionnaire, and NYHA functional class. ECG was recorded as 12-lead conventional ECG. Biochemistry assessments included electrolyte, urea, creatinine, glucose, aspartate and alanine aminotransferases, glutamyl transferase, and total and fraction of bilirubin. Hematology assessments included hematocrit, hemogram, and coagulation. We assessed BNP concentration with chemiluminescence using the TRIAGE test (Biosite, San Diego, CA). Echocardiography was done according to the American Society of Echocardiography guidelines, and the Simpson rule was used to calculate LVEF.

All examinations were done in each participating center, and the values were entered directly in the electronic case report form and immediately stored in 2 independent servers located at the National Cardiology Institute and at the Federal University of Rio de Janeiro (Rio de Janeiro, Brazil). Three investigators in each center were allowed to enter data using usernames and passwords attributed by the data coordinating center located at the National Cardiology Institute. These investigators were the hematologist who did bone marrow aspiration and BMNC processing, the interventional cardiologist who did catheterization for BMNC or placebo injection, and the cardiologist who followed up the patients during the study. Data were collected for the sequential phases of the study (Figure 1); data entry depended on completion of previous case report forms, without which the system was blocked, allowing remote monitoring of the study. A core laboratory at the National Cardiology Institute validated these values on the basis of random sampling of recorded examinations sent to the core laboratory.

The primary end point was the difference between groups in LVEF (expressed as trimmed mean and 95\% confidence interval) from baseline to 6 and 12 months in patients receiving optimized therapy for dilated chagasic cardiomyopathy. Secondary end points recorded at 6 and 12 months were differences between groups in NYHA functional class, mortality, physical capacity (by 6-minute walk test), quality of life (Minnesota questionnaire), and BNP concentrations.

The Data and Safety Monitoring Board was chosen among investigators of the other arms of the MiHeart Study. Meetings occurred every 2 months, and all changes in study protocol had to be approved by the independent Data and Safety Monitoring Board.

\section{Randomization and Masking}

Patients were randomly assigned (1:1 ratio) to receive autologous BMNC therapy or placebo. The randomization sequence was computer generated with $\mathrm{R}$ software (version 1.9.0). To ensure comparability between the treatment groups throughout the study, block randomization was used with block sizes of $2,4,6$, or 8 patients. To guarantee allocation concealment, we used an automated, Web-based randomization system situated at and managed by the coordinating center at the National Cardiology Institute in Rio de Janeiro, where randomization was generated by the Biostatistics Division. Patients, study staff, and investigators were masked to treatment assignment; the hematologist preparing the assigned treatment in each participating center was the only person who knew the randomization code. Identical $10-\mathrm{mL}$ syringes wrapped in dark plastic film to conceal contents were used to mask treatment assignment. The same strategy was used for the filgrastim injections.

\section{Sample Size and Statistical Analysis}

From analysis of data for patients with NYHA functional class II to IV heart failure who were treated in the National Cardiology Institute in the past 2 years, we concluded that LVEF followed an approximate gaussian distribution with a mean of $25 \%$ (SD, 10\%). Thus, for a $5 \%$ absolute difference in LVEF to be detected with a $95 \%$ confidence level, $80 \%$ statistical power, and a standard deviation of $15 \%$ (allowing for the multicenter design of the trial), a sample size of 142 patients per treatment group was needed. With a $2.5 \%$ loss to follow-up in 12 months, we calculated that we needed a sample size of 150 patients per treatment group.

Two assessments were scheduled: an interim analysis when the first 150 patients completed their 6-month follow-up and a final analysis when all 300 patients completed the 12-month follow-up. The O'Brien-Fleming stopping rule was followed; ie, for an overall $\alpha$ level of 0.05 , we used an $\alpha$ of 0.005 in the interim analysis and of 0.049 in the final analysis. The interim analysis showed a smaller dispersion than was expected, in fact a standard deviation of 8 instead of 15 . Therefore, under the same assumptions, the necessary sample size was reduced from 142 to 41 patients per treatment group.

BNP data were log transformed. If the patient died before an end point was measured, we imputed a fixed value for the variable that was worse than the worst value recorded for that variable. All imputed values correspond to deaths occurring during follow-up. We imputed 8 values for cell group at 6 months and 17 at 12 months. For the placebo group, we imputed 10 and 18 values at 6 and 12 months, respectively. Because the imputation of values for deaths renders the distribution of the variables nongaussian, we used robust statistical methods based on $10 \%$ trimmed distributions in all numeric variables analyses. Categorical data are presented as count (percentages) and numeric data as trimmed means; $95 \%$ confidence intervals were calculated for point estimates. Differences in numeric variables between groups were analyzed with the Yuen-Welch test ${ }^{11}$ (a robust analog of the $t$ test). Differences in NYHA functional class were analyzed with the $\chi^{2}$ test for trend. A secondary analysis of LVEF data was performed with the use of a robust repeated measures model. ${ }^{12}$ All analyses were performed on an intention-to-treat basis. Statistical analyses were done with R software (version 2.12), and we judged values of $P<0.05$ to be significant.

This trial is registered with http://www.clinicaltrials.gov (unique identifier: NCT00349271).

\section{Results}

\section{Enrollment and Characteristics of Patients}

Three of the 11 participating centers were excluded by the Data and Safety Monitoring Board after onsite monitoring showed protocol violations. Of the 464 patients assessed for eligibility, 224 did not meet inclusion criteria and 6 declined to participate. Thus, 234 patients were enrolled and random- 


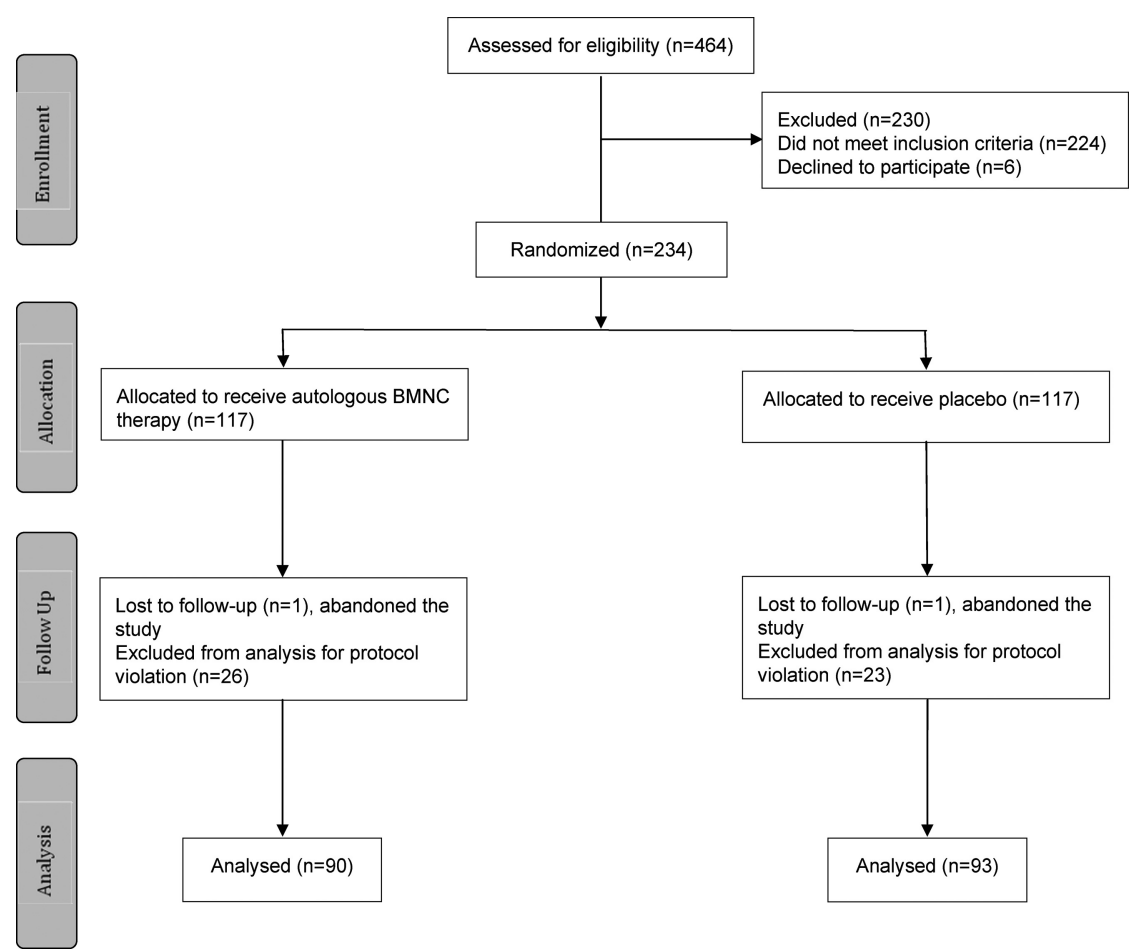

Figure 2. Study flow diagram. BMNC indicates bone marrow-derived mononuclear cell.

ized between July 2005 and October 2009, but 49 were not included in the analysis because they were enrolled by the 3 excluded centers, and 2 did not return for assessment even after active searching (Figure 2). The remaining 183 patients, 90 in the BMNC group and 93 in the placebo group, were treated and followed up between July 2005 and October 2010. The 2 treatment groups were well matched with respect to characteristics at baseline (Table 1); 126 (69\%) were men, the mean age was 52.4 years (50.8-54.0 years), and the LVEF was $26.1 \%(25.1 \%-27.1 \%)$. No patients examined had exclusion criteria for coronary artery disease. Thirty-five patients died during follow-up, but they were included in the intention-to-treat analysis.

\section{Cell Characterization}

Trimmed mean number of BMNCs did not differ between treatment groups. In the BMNC group, $2.5 \times 10^{8} \mathrm{BMNC}$ had a mean cell viability of 97.5 ; in the placebo group, $2.6 \times 10^{8}$ had a median cell viability of 98.2. The percentages of $\mathrm{CD}_{3} 4^{+}, \mathrm{CD}_{133^{+}}$, and $\mathrm{CD} 105^{+}$cells also did not differ significantly between treatment groups, as shown in Table 2.

\section{Outcomes}

No serious adverse events that could be directly related to the cell injection procedure were recorded during the trial. Continuous ECG monitoring during the 48 hours in the intensive care unit did not detect an increase in lifethreatening arrhythmias. Trimmed mean creatinine kinase-MB enzyme levels at 0 (just before), 12, and 24 hours after the catheterization procedure were $8.7,8.8$, and $8.8 \mathrm{mg} / \mathrm{dL}$ for the BMC group and $10.8,8.7$, and $8.5 \mathrm{mg} / \mathrm{dL}$ for the placebo group $(P=0.114, P=0.981$, and $P=0.841$, respectively). Edema, pain, and swelling were the most common complaints after bone marrow aspiration and catheterization.

Although this trial was not powered to detect betweengroup differences in mortality, mortality was similar: 18 $(19.4 \%)$ in the placebo group, and $17(18.9 \%)$ in the BMNC group. In analysis of the primary end point in the BMNC group, trimmed mean LVEF increased from $26.1 \%$ at baseline to $28.9 \%$ at 6 months and $29.6 \%$ at 12 months (Table 3 ). In the placebo group, LVEF increased from $26.1 \%$ at baseline to $29.8 \%$ at 6 months and $31.3 \%$ at 12 months (Table 3). However, change in LVEF from baseline to 12 months did not differ significantly between treatment groups (Table 3). Notably, 35 patients $(37.6 \%)$ in the placebo group equivocally received 5 days of filgrastim injections at 25 days after intracoronary saline injection. Because analysis was by intention to treat, these patients were still included in the final analysis. However, to exclude the possibility that filgrastim injections improved LVEF in the placebo group, thus masking a positive effect of BMNC therapy, we reanalyzed the data with robust 2-way ANOVA model. For 6-month data, $P=0.801$ for the BMNC effect, $P=0.777$ for the filgrastim effect, and $P=0.385$ for the interaction between them. For 12-month data, $P=0.677, P=0.815$, and $P=0.793$, respectively. Again, statistical analysis showed no between-group difference. Additionally, exclusion of the randomization blocks containing the patients who received filgrastim in the placebo group resulted in an analysis population of 58 patients per group, which provided sufficient statistical power to analyze the efficacy of the therapy. Even under these conditions, we recorded no significant between-group differences for any of the variables analyzed.

Left ventricular diastolic and systolic volumes at baseline and the 6- and 12-month follow-up are presented in Table 4. The change in volumes during the study and the between- 
Table 1. Baseline Characteristics of Patients

\begin{tabular}{lcc}
\hline & $\begin{array}{c}\text { Placebo Group } \\
(\mathrm{n}=93)\end{array}$ & $\begin{array}{c}\text { BMNC Group } \\
(\mathrm{n}=90)\end{array}$ \\
\hline Age, y & $52.4(50.1-54.7)$ & $52.4(50.3-54.5)$ \\
Men, $\mathrm{n}(\%)$ & $68(73.1)$ & $58(64.4)$ \\
LVEF, \% & $26.1(24.7-27.6)$ & $26.1(24.8-27.3)$ \\
LVDv, $\mathrm{mL}$ & $253.3(236.7-269.9)$ & $247.7(227.5-267.8)$ \\
LVSv, mL & $171.1(156.3-185.9)$ & $162.0(144.8-179.1)$ \\
6-min walking distance, $\mathrm{m}$ & $370.2(348.8-391.7)$ & $363.5(330.0-396.4)$ \\
MLQQ score & $44.5(40.0-49.1)$ & $46.3(40.9-51.8)$ \\
InBNP, pg/mL & $3.5(2.9-4.0)$ & $3.1(2.5-3.7)$ \\
ACEi, \% & 65.9 & 66.0 \\
ARB, \% & 24.2 & 22.3 \\
Hydralazine, \% & 4.4 & 5.3 \\
Nitrates, \% & 1.1 & 1.1 \\
Furosemide, \% & 89.0 & 92.6 \\
Spironolactone, \% & 86.8 & 91.5 \\
Hydroclorothiazide, \% & 27.5 & 28.7 \\
Digoxin, \% & 72.5 & 62.8 \\
Amiodarone, \% & 48.4 & 57.4 \\
Carvedilol, \% & 65.9 & 69.1 \\
Other $\beta$-blockers, \% & 6.6 & 3.2 \\
\hline BMNC $n$ & & \\
\hline
\end{tabular}

BMNC indicates bone marrow-derived mononuclear cell; LVEF, left ventricular ejection fraction; LVDd, left ventricular diastolic diameter; LVSd, left ventricular systolic diameter; MLQQ, Minnesota life-quality questionnaire; LnBNP, natural logarithm of the brain natriuretic peptide concentration; ACEi, angiotensin-converting enzyme inhibitor; and ARB, angiotensin receptor blocker. Data are trimmed mean ( $95 \%$ confidence interval), number $(\%)$, or percentage of patients taking medication as appropriate.

group differences were not significant. Furthermore, change in NYHA functional class did not differ significantly between the groups at 6 months $(P=0 \cdot 949)$ and 12 months $(P=0.664$; Figure 3).

The Minnesota quality-of-life questionnaire trimmed mean score significantly improved in the BMNC group from 46.3 (40.9-51.8) at baseline to $25.3(19.2-31.3)$ at 6 months $(P<0.001)$ and $22.3(16.2-28.5)$ at 12 months $(P<0.001)$; it improved in the placebo group from $44.5(40.0-49.1)$ at baseline to $21.2(16.1-26.3)$ at 6 months $(P<0.001)$ and 22.6 (17.1-28.1) at 12 months $(P<0.001)$. However, the change in

Table 2. Cell Characteristics of the Bone Marrow-Derived Mononuclear Cell and Placebo Groups

\begin{tabular}{lcc}
\hline & BMNC Group & Placebo Group \\
\hline Total cells, $\times 10^{8}$ & $2.5(1.9-3.1)$ & $2.6(1.9-3.3)$ \\
Viability by trypan blue exclusion & $97.5(97.0-98.1)$ & $98.2(97.7-98.6)$ \\
CD34 cells, \% & $2.0(1.3)^{\star}$ & $2.2(1.7) \dagger$ \\
CD133 cells, \% & $1.4(1.6)^{\star}$ & $1.7(1.8) \dagger$ \\
CD105 cells, \% & $1.3(0.9)^{\star}$ & $1.6(1.0) \dagger$ \\
\hline
\end{tabular}

BMNC indicates bone marrow-derived mononuclear cell. Values are trimmed mean $(95 \%$ confidence interval for the first 2 rows or SD for the last 3 rows). There are no significant differences between groups.

*Nineteen patients declined participation or had insufficient product for analysis.

†Ten patients declined participation.
Table 3. Left Ventricular Ejection Fraction Values at Baseline and at the 6- and 12-Month Follow-Up

\begin{tabular}{lccc}
\hline & $\begin{array}{c}\text { Placebo Group } \\
(\mathrm{n}=93)\end{array}$ & $\begin{array}{c}\text { BMNC Group } \\
(\mathrm{n}=90)\end{array}$ & $P$ \\
\hline Baseline, \% & $26 \cdot 1(24.7-27.6)$ & $26.1(24.8-27.3)$ & 0.985 \\
At $6 \mathrm{mo}, \%$ & $29.6(27.6-31.7)$ & $29.3(27.4-31.1)$ & 0.780 \\
Difference from & $2.5(0.6-4.5)$ & $3.0(1.3-4.8)$ & 0.519 \\
baseline, \% & & & \\
$P$ & 0.0125 & 0.001 & $\ldots$ \\
At $12 \mathrm{mo} \%$ \% & $31.1(28.7-33.6)$ & $30.2(27.9-32.4)$ & 0.559 \\
Difference from & $3.7(1.5-6.0)$ & $3.5(1.5-5.5)$ & 0.850 \\
baseline, \% & & & \\
$P$ & 0.002 & 0.001 & $\ldots$ \\
\hline \multicolumn{2}{r}{ BMNC indicates bone marrow-derived mononuclear cell. Data are trimmed }
\end{tabular}

BMNC indicates bone marrow-derived mononuclear cell. Data are trimmed mean (95\% confidence interval).

score did not differ between groups at 6 months $(P=0.130)$ and 12 months $(P=0.819)$. The trimmed means of the natural logarithm of BNP concentrations varied from $3.1 \mathrm{pg} / \mathrm{mL}$ at baseline to $3.4 \mathrm{pg} / \mathrm{mL}$ at 6 months $(P=0.422)$ and $3.6 \mathrm{pg} / \mathrm{mL}$ at 12 months $(P=0.141)$ in the BMNC group and from 3.5 $\mathrm{pg} / \mathrm{mL}$ at baseline to $3.1 \mathrm{pg} / \mathrm{mL}$ at 6 months $(0.347)$ and 3.1 $\mathrm{pg} / \mathrm{mL}$ at 12 months $(P=0.315)$ in the placebo group. Change in BNP concentrations also did not differ significantly between groups at 6 months $(P=0.376)$ and 12 months $(P=0.217)$. Six-minute walking distance increased significantly in both groups but did not differ significantly between groups (Table 5).

Table 4. Left Ventricular Diastolic and Systolic Volumes at Baseline and at the 6- and 12-Month Follow-Up

\begin{tabular}{lccc}
\hline & $\begin{array}{c}\text { Placebo Group } \\
(\mathrm{n}=93)\end{array}$ & $\begin{array}{c}\text { BMNC Group } \\
\text { ( } \mathrm{n}=90)\end{array}$ & $P$ \\
\hline LVdV, mL & & & \\
Baseline & $253.3(236.7-269.9)$ & $247.7(227.5-267.8)$ & 0.665 \\
At 6 mo & $246.2(227.2-265.1)$ & $248.8(226.1-270.1)$ & 0.894 \\
Difference & $2.4(-15.9$ to 11.2) & $0.7(-12.8$ to 14.1) & 0.882 \\
from baseline & & & \\
$P$ & 0.729 & 0.920 & \\
At 12 mo & $251.2(230.9-271.6)$ & $250.8(229.5-272.1)$ & 0.975 \\
Difference & $10.4(-8.0$ to 28.7) & $7.8(-7.6$ to 28.7) & 0.801 \\
from baseline & & & \\
$P$ & 0.261 & 0.296 & \\
LVsV, mL & & & 0.422 \\
Baseline & $171.1(156.3-185.9)$ & $162.0(144.8-179.1)$ & \\
At 6 mo & $171.3(154.4-188.1)$ & $164.0(145.2-182.7)$ & 0.552 \\
Difference & $7.2(-5.4$ to 19.7) & $2.6(-10.2$ to 15.5) & 0.889 \\
from baseline & & & \\
$P$ & 0.258 & 0.685 & \\
12 mo & $167.2(150.6-183.8)$ & $162.8(145.0-180.5)$ & 0.712 \\
Difference & $9.8(-3.1$ to 22.7) & $6.4(-8.9$ to 21.7) & 0.734 \\
from baseline & & 0.406 & \\
$P$ & 0.135 & & \\
\hline
\end{tabular}

BMNC indicates bone marrow-derived mononuclear cell; LVdV, left ventricular diastolic volume; and LVsV, left ventricular systolic volume. Data are trimmed mean ( $95 \%$ confidence interval). 


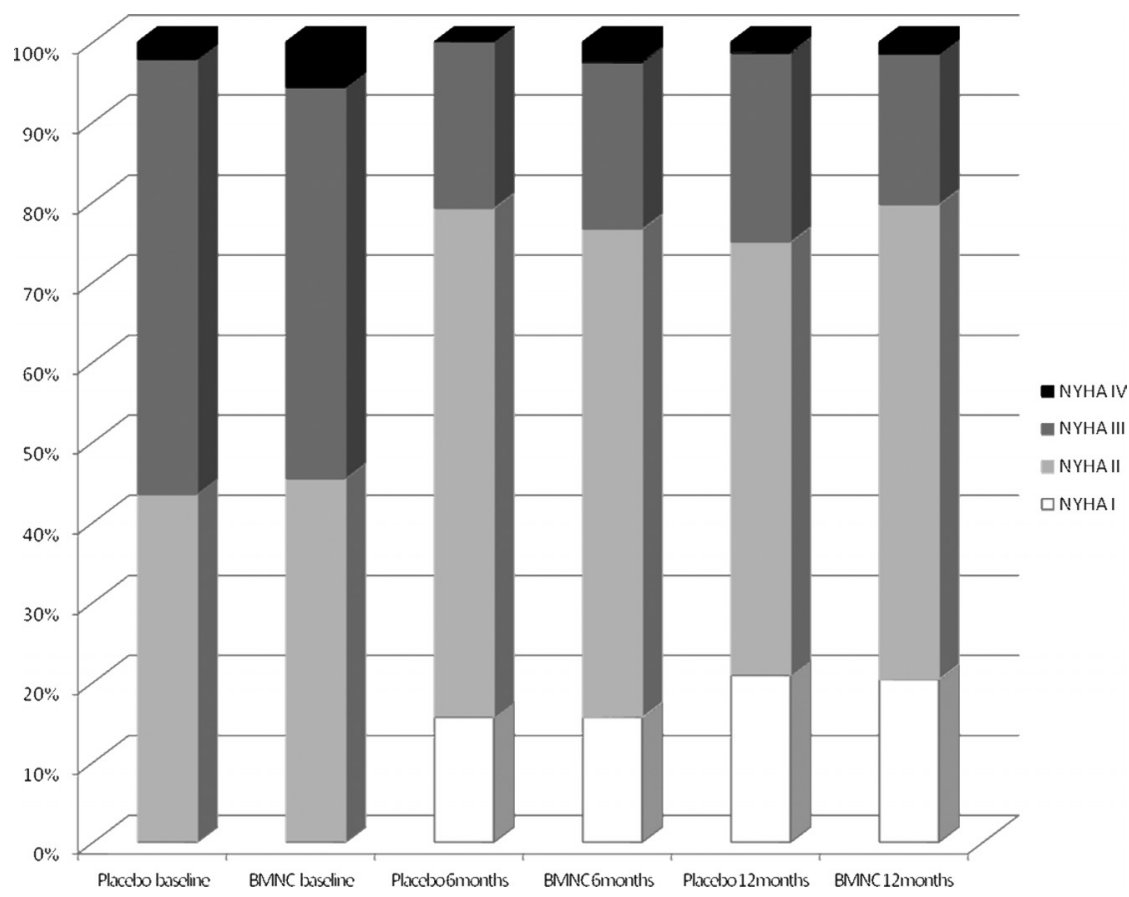

Figure 3. New York Heart Association (NYHA) functional class during follow-up. Values are presented as percent of patients in each NYHA class at baseline and at the 6- and 12-month follow-up for both groups. BMNC indicates bone marrow-derived mononuclear cell.

Repeated measures analysis of the primary end point (LVEF) also did not detect significant differences between the 2 treatment groups $(P$ of the BMNC effect $=0.521)$.

\section{Discussion}

The findings of our study show that intracoronary injection of BMNCs in patients with CCC does not lead to further improvement in LVEF or other indicators of disease compared with standard therapy. However, our study adds to the notion that intracoronary BMNC therapy is safe in these patients, as previously reported by Vilas-Boas et al. ${ }^{8,9} \mathrm{BMNC}$ therapy has been used in various cardiopathies with an almost unanimous safety profile (for a review, see the work by Martin-Rendon and colleagues ${ }^{13}$ ). In the few instances when safety issues were raised, ${ }^{14}$ additional studies did not confirm the reported adverse events. ${ }^{15,16}$ In our study, no serious adverse events related to the procedure were recorded in the 90 patients analyzed in the BMNC group, even though our study population had very poor health.

Table 5. Six-Minute Walking Distance at Baseline and at the 6- and 12-Month Follow-Up

\begin{tabular}{lccc}
\hline & Placebo Group & BMNC Group & $P$ \\
\hline Baseline & $370.2(348.8-391.7)$ & $363.5(330.0-396.9)$ & 0.735 \\
At 6 mo & $416.6(388.1-445.1)$ & $422.7(387.9-457.4)$ & 0.782 \\
Difference from & $46.9(15.9-78.0)$ & $56.0(24.6-87.4)$ & 0.756 \\
baseline & & & \\
$P$ & 0.003 & 0.001 & \\
At 12 mo & $416.0(326.6-455.3)$ & $427.8(388.7-467.1)$ & 0.663 \\
$\begin{array}{l}\text { Difference from } \\
\text { baseline }\end{array}$ & $41.9(2.2-81.6)$ & $63.4(33.5-93.4)$ & 0.870 \\
$P$ & & & \\
\hline
\end{tabular}

BMNC indicates bone marrow-derived mononuclear cell. Data are trimmed mean $(95 \%$ confidence interval).
Although LVEF significantly increased from baseline to 6 and 12 months in the BMNC group, this improvement was also seen in the placebo group. The $4 \%$ absolute increase in LVEF recorded 6 months after BMNC therapy in our study is similar to that reported by Vilas-Boas and colleagues $^{8}$ in their pioneering study and highlights the need for placebo-controlled randomized trials to assess the efficacy of cell-based therapies. Although the Vilas-Boas et al study was performed in a population with lower baseline LVEF (20\% versus $26 \%$ in our study), we do not think that a $6 \%$ absolute difference in LVEF at baseline could influence the results, even more when we are comparing a safety trial with an efficacy trial. At any rate, a linear regression using the change in LVEF compared with baseline LVEF does not show significant correlation $\left(R^{2}=0.000001, P=0.989\right)$.

The statistically significant increase in LVEF in both groups in our trial indicates that this study population deserves improved medical attention; even though we did at least 6 weeks of pharmacological optimization, this period was clearly not long enough to achieve the patients' best cardiac performance. Most patients with CCC belong in the lower socioeconomic stratum of the population; therefore, privileged access to medical services and free drug prescriptions would, unsurprisingly, lead to improvement in health.

The lack of benefit of BMNC therapy in CCC might stem from the complex and multivariate pathological basis of this disease. CCC is known to involve cycles of parasitic eclosion, resulting in inflammatory invasion and destruction of cardiomyocytes ${ }^{17}$ and autoimmune and microvascular disorders $^{18}$ that compromise the working myocardium and conduction system. Although BMNC therapy significantly decreases cardiac inflammation and fibrosis in a mouse model of chronic chagasic infection, ${ }^{7}$ left ventricular 
dysfunction has not been described in this model. In fact, Goldenberg and colleagues ${ }^{19}$ showed only a dilatation of right ventricular chamber in this mouse model, raising doubts about the validity of the model to represent human cardiac dysfunction.

Another plausible explanation for the lack of benefit is that BMNCs might not be able to induce cardiomyogenesis. CCC involves destruction of cardiomyocytes, which means that a clear benefit, especially if LVEF is used as a surrogate end point, would ensue only if BMNC therapy regenerates lost cardiomyocytes. Although randomized trials of BMNC therapy in acute ischemic heart disease have reported a significant gain in $\mathrm{LVEF},{ }^{20,21}$ even if temporary, or a reduction in infarct area, ${ }^{22}$ this result is probably caused by increased angiogenesis stimulated by BMNC therapy, not by cardiomyogenesis. In Chagas heart disease, cell homing occurs in well-perfused areas after intracoronary cell injection ${ }^{23}$; therefore, the angiogenic effect of BMNC therapy might not be available where it is most needed in CCC.

This study has limitations imposed by the infrastructure of the collaborating centers; very few centers were equipped with magnetic resonance imaging, and we had to evaluate LVEF by echocardiography. Furthermore, the validation of the echocardiograms by sampling in the core laboratory is another study limitation. Cell processing at each collaborating center might be considered another limitation, but we reasoned that a centralized cell processing laboratory would require freeze/thawing of the cells given the distances between participating centers, a much greater limitation for cell quality in our view. The use of granulocyte colony-stimulating factor in a percentage of the patients of the placebo group could have limited the validity of our study. However, as mentioned earlier, even after exclusion of all randomization blocks containing these patients, we still had statistical power to analyze the data.

Intracoronary BMNC therapy does not have additional benefits over standard therapy for CCC in patients with severe heart failure. However, this finding should not deter researchers from testing new cell types, injection routes, and time windows for the start of therapy because this intractable disease leaves patients with end-stage heart failure with no treatment option other than heart transplantation.

\section{Acknowledgments}

We would like to thank Dr Timothy Henry for his role as an international consultant to this study.

\section{Sources of Funding}

This trial was funded by the Brazilian Ministry of Health.

\section{Disclosures}

None.

\section{References}

1. Rassi A, Rassi A, Marin-Neto JA. Chagas disease. Lancet. 2010;375: $1388-1402$.
2. Chagas C. Nova tripanozomiaze humana: estudos sobre a morfolojia e o ciclo evolutivo do Schizotrypanum cruzi n. gen., n. sp., ajente etiolojico de nova entidade morbida do homem. Memórias do Instituto Oswaldo Cruz. 1909;1:159-218.

3. Kierszenbaum F. Where do we stand on the autoimmunity hypothesis of Chagas disease? Trends Parasitol. 2005;21:513-516.

4. Andrade ZA, Andrade SG. Pathogenesis of Chagas' chronic myocarditis; importance of ischemic lesions [in Portuguese]. Arq Bras Med. 1955;45: 279-288.

5. Andrade ZA, Lopes EA. A histochemical study of experimental Chagas' disease. Rev Inst Med Trop São Paulo. 1963;5:236-242.

6. Freitas HFG, Chizzola PR, Paes AT, Lima ACP, Mansur AJ. Risk stratification in a Brazilian hospital-based cohort of 1220 outpatients with heart failure: role of Chagas' heart disease. Int J Cardiol. 2005;102: 239-247.

7. Soares MBP, Lima RS, Rocha LL, Takyia CM, Pontes-de-Carvalho L, de Carvalho ACC, Ribeiro-dos-Santos R. Transplanted bone marrow cells repair heart tissue and reduce myocarditis in chronic chagasic mice. Am J Pathol. 2004;164:441-447.

8. Vilas-Boas F, Feitosa GS, Soares MBP, Mota A, Pinho-Filho JA, Almeida AJG, Andrade MV, Carvalho HG, Dourado-Oliveira A, Ribeirodos-Santos R. Early results of bone marrow cell transplantation to the myocardium of patients with heart failure due to Chagas disease. Arq Bras Cardiol. 2006;87:159-166.

9. Vilas-Boas F, Feitosa GS, Soares MBP, Pinho-Filho JÁ, Mota A, Almeida AJG, Andrade MS, Carvalho HG, Oliveira AD, Ribeiro-dosSantos R. Bone marrow cell transplantation in Chagas' disease heart failure: report of the first human experience. Arq Bras Cardiol. 2011;96: $325-331$.

10. Theodoropoulos TAD, Bestetti RB, Otaviano AP, Cordeiro JA, Rodrigues VC, Silva AC. Predictors of all-cause mortality in chronic Chagas' heart disease in the current era of heart failure therapy. Int J Cardiol. 2008;128:22-29.

11. Yuen KK. The two sample trimmed $t$ test for unequal population variances. Biometrika. 1974;61:165-170.

12. Wilcox RR. Analyzing repeated measures or randomized block designs using trimmed means. Br J Math Stat Psychol. 1993;46:63-76.

13. Martin-Rendon E, Brunskill SJ, Hyde CJ, Stanworth SJ, Mathur A, Watt SM. Autologous bone marrow stem cells to treat acute myocardial infarction: a systematic review. Eur Heart J. 2008;29: 1807-1818.

14. Kang H-J, Kim H-S, Zhang S-Y, Park K-W, Cho H-J, Koo B-K, Kim YJ, Soo Lee D, Sohn DW, Han KS, Oh BH, Lee MM, Park YB. Effects of intracoronary infusion of peripheral blood stem-cells mobilised with granulocyte-colony stimulating factor on left ventricular systolic function and restenosis after coronary stenting in myocardial infarction: the MAGIC cell randomised clinical trial. Lancet. 2004;363:751-756.

15. Assmus B, Walter DH, Lehmann R, Honold J, Martin H, Dimmeler S, Zeiher AM, Schächinger V. Intracoronary infusion of progenitor cells is not associated with aggravated restenosis development or atherosclerotic disease progression in patients with acute myocardial infarction. Eur Heart J. 2006;27:2989-2995.

16. Abdel-Latif A, Bolli R, Zuba-Surma EK, Tleyjeh IM, Hornung CA, Dawn B. Granulocyte colony-stimulating factor therapy for cardiac repair after acute myocardial infarction: a systematic review and meta-analysis of randomized controlled trials. Am Heart J. 2008;156: 216-226.e9.

17. Higuchi ML. Chagas disease: importance of the parasite in the pathogenesis of the cardiac chronic disease. Arq Bras Cardiol. 1995;64: 251-254.

18. Tanowitz HB, Machado FS, Jelicks LA, Shirani J, de Carvalho ACC, Spray DC, Factor SM, Kirchhoff LV, Weiss LM. Perspectives on Trypanosoma cruzi-induced heart disease (Chagas disease). Prog Cardiovasc Dis. 2009;51:524-539.

19. Goldenberg RCS, Jelicks LA, Fortes FSA, Weiss LM, Rocha LL, Zhao D, Carvalho AC, Spray DC, Tanowitz HB. Bone marrow cell therapy ameliorates and reverses chagasic cardiomyopathy in a mouse model. J Infect Dis. 2008;197:544-547.

20. Wollert KC, Meyer GP, Lotz J, Ringes-Lichtenberg S, Lippolt P, Breidenbach C, Fichtner S, Korte T, Hornig B, Messinger D, Arseniev 
L, Hertenstein B, Ganser A, Drexler H. Intracoronary autologous bone-marrow cell transfer after myocardial infarction: the BOOST randomised controlled clinical trial. Lancet. 2004;364:141-148.

21. Schächinger V, Erbs S, Elsässer A, Haberbosch W, Hambrecht R, Hölschermann H, Yu J, Corti R, Mathey DG, Hamm CW, Süselbeck T, Assmus B, Tonn T, Dimmeler S, Zeiher AM; REPAIR-AMI Investigators. Intracoronary bone marrow-derived progenitor cells in acute myocardial infarction. N Engl J Med. 2006;355:1210-1221.

22. Janssens S, Dubois C, Bogaert J, Theunissen K, Deroose C, Desmet W, Kalantzi M, Herbots L, Sinnaeve P, Dens J, Maertens J, Rademakers F,
Dymarkowski S, Gheysens O, Van Cleemput J, Bormans G, Nuyts J, Belmans A, Mortelmans L, Boogaerts M, Van de Werf F. Autologous bone marrow-derived stem-cell transfer in patients with ST-segment elevation myocardial infarction: double-blind, randomised controlled trial. Lancet. 2006;367:113-121.

23. Barbosa da Fonseca LM, Xavier SS, Rosado de Castro PH, Lima RSL, Gutfilen B, Goldenberg RCS, Maiolino A, Chagas CL, Pedrosa RC, Campos de Carvalho AC. Biodistribution of bone marrow mononuclear cells in chronic chagasic cardiomyopathy after intracoronary injection. Int J Cardiol. 2011;149:310-314.

\section{CLINICAL PERSPECTIVE}

Heart failure is a common cause of death in patients with chronic chagasic cardiomyopathy. Current therapies are limited and, with the exception of heart transplantation, only delay disease progression. Cell therapy using bone marrow-derived cells has been a promising (albeit inconsistent) approach to the treatment of cardiovascular diseases. Experimental evidence in animal models and feasibility studies in patients with chronic chagasic cardiomyopathy have suggested that bone marrow mononuclear cell transplantation may improve cardiac function. This study reports the results of a multicenter, double-blind, randomized, placebo-controlled trial evaluating the efficacy of bone marrow mononuclear cells on left ventricular ejection fraction in 183 patients with chronic chagasic cardiomyopathy. Although both the placebo and cell-therapy groups showed a significant increase in left ventricular ejection fraction at 6 and 12 months of follow-up, this study failed to document a significant difference in change in left ventricular ejection fraction between the 2 groups. Intracoronary injection of bone marrow mononuclear cells was not associated with adverse clinical events. We conclude that with the methods used, no additional benefit of intracoronary mononuclear cell injection was found in patients with chronic chagasic cardiomyopathy and a left ventricular ejection fraction $<35 \%$. Nonetheless, cell-based therapies may still hold promise for chronic chagasic cardiomyopathy patients. Larger clinical trials focusing on hard clinical end points, new cell types, methods of delivery, dosage schemes, and disease stages are warranted to further test the efficacy of this novel therapeutic approach. 


\section{Circulation}

\section{Cell Therapy in Chagas Cardiomyopathy (Chagas Arm of the Multicenter Randomized Trial of Cell Therapy in Cardiopathies Study): A Multicenter Randomized Trial}

Ricardo Ribeiro dos Santos, Salvador Rassi, Gilson Feitosa, Oswaldo T. Grecco, Anis Rassi, Jr, Ademir B. da Cunha, Valéria B. de Carvalho, Luiz César Guarita-Souza, Wilson de Oliveira, Jr, Bernardo R. Tura, Milena B.P. Soares and Antonio C. Campos de Carvalho

Circulation. 2012;125:2454-2461; originally published online April 20, 2012; doi: 10.1161/CIRCULATIONAHA.111.067785

Circulation is published by the American Heart Association, 7272 Greenville Avenue, Dallas, TX 75231

Copyright $\odot 2012$ American Heart Association, Inc. All rights reserved.

Print ISSN: 0009-7322. Online ISSN: 1524-4539

The online version of this article, along with updated information and services, is located on the World Wide Web at:

http://circ.ahajournals.org/content/125/20/2454

Data Supplement (unedited) at:

http://circ.ahajournals.org/content/suppl/2012/04/19/CIRCULATIONAHA.111.067785.DC1

Permissions: Requests for permissions to reproduce figures, tables, or portions of articles originally published in Circulation can be obtained via RightsLink, a service of the Copyright Clearance Center, not the Editorial Office. Once the online version of the published article for which permission is being requested is located, click Request Permissions in the middle column of the Web page under Services. Further information about this process is available in the Permissions and Rights Question and Answer document.

Reprints: Information about reprints can be found online at: http://www.lww.com/reprints

Subscriptions: Information about subscribing to Circulation is online at: http://circ.ahajournals.org//subscriptions/ 


\section{Supplemental Material}

\section{Chagas Arm of the MiHeart Study Investigators}

Fábio Vilas-Boas, MD, PhD, Augusto Mota, MD, PhD, Joel Alves Pinho-Filho, MD, Augusto José Gonçalves Almeida, MD, Marcus Vinicius Andrade, MD, Hospital Santa Isabel, Salvador, BA;

Patrícia C dos Santos Costa, PhD, Fabiana Bergamin Muccillo, Luciano

Belem, Fernando Cesar Castro e Souza, MD, César Augusto da Silva Nascimento, MD, Rafael Lauria de Oliveira, MD, Bráulio Santos, MD Instituto Nacional de Cardiologia, Rio de Janeiro, RJ;

Anis Rassi, MD, Vinicius Daher Vaz, MD, César Leite Sant'Anna, MD, Hospital Anis Rassi, Goiania, GO;

Enieberton Cartafina, MD, Renato, Gustavo Carvalho, MD, Mário Henrique Miguel da Silva, Sampaio Tavares, MD, PhD, Hospital das Clínicas- UFG, Goiania, GO;

Milton A. Ruiz, MD, PhD, José Luiz Jacob, MD, PhD, Adelino Parro Jr, MD, Instituto de Moléstias Cardiovasculares, São Paulo, SP;

Carlos Eduardo Suaide Silva, MD, PhD, FACC, Silvano Wendel MD, PhD, Antonio Esteves Filho, MD, Enis Domizetti Silva, Luiz Junya Kajita, MD, Hospital Sírio e Libanes, São Paulo;

Márcia Miyazaki, MD, Katherine Athayde Teixeira de Carvalho, MD, PhD, Julio César Francisco, Lásaro Garcia, MD Pontifícia Universidade Católica do Paraná, Curitiba, PR. 


\section{Supplemental Table}

The antibody panel used for cell characterization is shown in the Table. For determination of CD34 ${ }^{+}$cell content we used the ISHAGE protocol ${ }^{1}$.

\begin{tabular}{|l|l|l|l|}
\hline $\begin{array}{l}\text { monoclonal antibodies } \\
\text { (MoAb) }\end{array}$ & $\begin{array}{l}\text { fluorochrom } \\
\text { es }\end{array}$ & company & $\begin{array}{l}\text { catalog } \\
\text { number }\end{array}$ \\
\hline CD3 & PE & BD & 347347 \\
\hline CD4 & PERCP & BD & 347324 \\
\hline CD8 & FITC & BD & 347313 \\
\hline CD14 & PE & BD & 347497 \\
\hline CD19 & FITC & BD & 347453 \\
\hline CD31 & FITC & $\begin{array}{l}\text { BD } \\
\text { PHARMIGEN }\end{array}$ & 557508 \\
\hline CD33 & PECY7 & BD & 333949 \\
\hline CD34 & PECY7 & BD & 348801 \\
\hline CD45 & APC & BD & 340942 \\
\hline CD54 & PECY5 & BD & 555512 \\
\hline CD56 & PE & BD & 347747 \\
\hline CD64 & FITC & $\begin{array}{l}\text { BD } \\
\text { PHARMIGEN }\end{array}$ & 555527 \\
\hline CD73 & PE & $\begin{array}{l}\text { BD } \\
\text { PHARMIGEN }\end{array}$ & 550257 \\
\hline CD90 & PECY5 & $\begin{array}{l}\text { BD } \\
\text { PHARMIGEN }\end{array}$ & 555597 \\
\hline CD105 & FITC & IMMUNOSTEP & 2209060105 \\
\hline CD117 & PECY5 & BD & 339195 \\
\hline CD146 & PE & $\begin{array}{l}\text { BD } \\
\text { PHARMIGEN }\end{array}$ & 550315 \\
\hline CD166 & PE & $\begin{array}{l}\text { BD } \\
\text { PHARMIGEN }\end{array}$ & 559263 \\
\hline CD133/2 & PE & $\begin{array}{l}\text { BD } \\
\text { PHARMIGEN }\end{array}$ & 130090853 \\
\hline CD51/61 & PECY5 & $\begin{array}{l}\text { BD } \\
\text { PHARMIGEN }\end{array}$ & 55505 \\
\hline Bcrp/abcg2 & PE & $\begin{array}{l}\text { BD } \\
\text { PHARMIGEN }\end{array}$ & 551375 \\
\hline CXCR4 & FAB995P \\
\hline HLA-DR & PE & \\
\hline & PE & \\
\hline
\end{tabular}

1

1. SUTHERLAND, D.R., ANDERSON, L., KEENEY, M., NAYAR, R. \& CHIN-YEE, I. The ISHAGE guidelines for CD34+ cell determination by flow cytometry. Journal of hematotherapy 1996; 5: 213-226. 